\title{
Erratum to: What is the role of trees and remnant vegetation in attracting people to urban parks?
}

\author{
D. F. Shanahan - B. B. Lin · K. J. Gaston • \\ R. Bush • R. A. Fuller
}

Published online: 6 February 2015

(C) Springer Science+Business Media Dordrecht 2015

\section{Erratum to: Landscape Ecol (2015) 30:153-165 \\ DOI 10.1007/s10980-014-0113-0}

In the original publication, Table 2 has been published incorrectly. The correct Table 2 is given below.

The online version of the original article can be found under doi:10.1007/s10980-014-0113-0.

D. F. Shanahan $(\bowtie) \cdot$ R. A. Fuller

School of Biological Sciences, University of Queensland, St Lucia, Brisbane, QLD 4072, Australia e-mail: danielleshanahan@gmail.com

\section{B. B. Lin} CSIRO Climate Adaptation Flagship and CSIRO Marine and Atmospheric Research, PMB 1, 107-121 Station

Street, Aspendale, VIC 3195, Australia

\section{K. J. Gaston}

Environment \& Sustainability Institute, University of Exeter, Penryn, Cornwall TR10 9EZ, UK

R. Bush

School of Population Health, University of Queensland, Herston, Brisbane, QLD 4006, Australia 


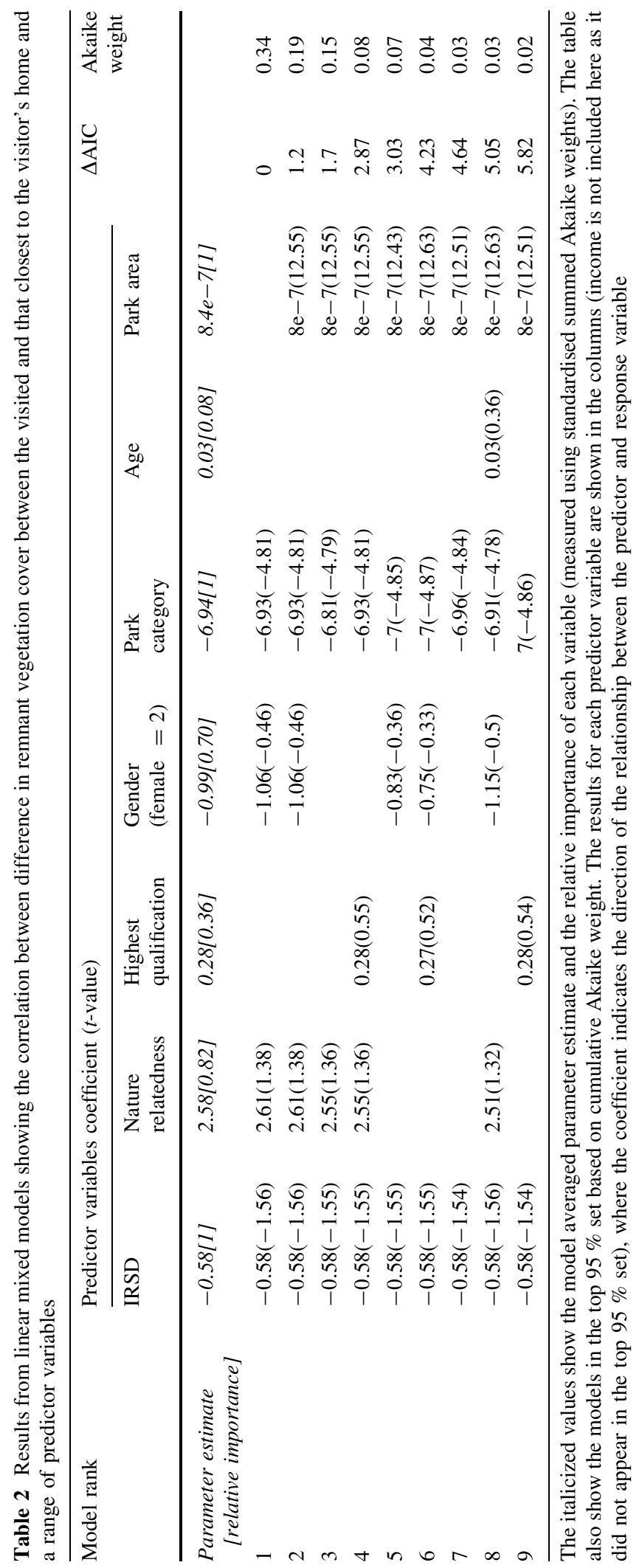

